\title{
Mechanistic basis of adaptive maternal effects: egg jelly water balance mediates embryonic adaptation to acidity in Rana arvalis
}

\author{
Longfei Shu ${ }^{1,2,6} \cdot$ Marc J.-F. Suter $^{3,4} \cdot$ Anssi Laurila $^{5} \cdot$ Katja Räsänen $^{1,2}$
}

Received: 22 July 2014 / Accepted: 25 April 2015 / Published online: 17 May 2015

(C) Springer-Verlag Berlin Heidelberg 2015

\begin{abstract}
Environmental stress, such as acidification, can challenge persistence of natural populations and act as a powerful evolutionary force at ecological time scales. The ecological and evolutionary responses of natural populations to environmental stress at early life-stages are often mediated via maternal effects. During early life-stages, maternal effects commonly arise from egg coats (the extracellular structures surrounding the embryo), but the role of egg coats has rarely been studied in the context of adaptation
\end{abstract}

Communicated by William J. Resetarits.

Research highlight: This research increases our understanding of the ecological and evolutionary role of egg coats, which are maternally derived extracellular structures that surround the organism during early life stages. This study revealed that acid stress could cause severe water loss of egg jelly and likely imposed strong selection on water balance of egg jelly in amphibians by reduced embryonic hatching success. In addition, this study suggested that a "pH-jelly water balance" model, mediated via intra-specific glycan variability, may help explaining the molecular basis of embryonic adaptation to acid stress and egg-coat mediated adaptive maternal effects. Moreover, this model can be extended to other aquatic systems in both vertebrate and invertebrate taxa.

Electronic supplementary material The online version of this article (doi:10.1007/s00442-015-3332-4) contains supplementary material, which is available to authorized users.

Longfei Shu

longfei.shu@wustl.edu

1 Department of Aquatic Ecology, Eawag, 8600 Dübendorf, Switzerland

2 Institute of Integrative Biology, ETH Zürich, 8092 Zürich, Switzerland

3 Department of Environmental Toxicology, Eawag, 8600 Dübendorf, Switzerland to environmental stress. Previous studies on the moor frog Rana arvalis found that the egg coat mediated adaptive divergence along an acidification gradient in embryonic acid stress tolerance. However, the exact mechanisms underlying these adaptive maternal effects remain unknown. Here, we investigated the role of water balance and charge state (zeta potential) of egg jelly coats in embryonic adaptation to acid stress in three populations of $R$. arvalis. We found that acidic $\mathrm{pH}$ causes severe water loss in the egg jelly coat, but that jelly coats from an acid-adapted population retained more water than jelly coats from populations not adapted to acidity. Moreover, embryonic acid tolerance (survival at $\mathrm{pH}$ 4.0) correlated with both water loss and charge state of the jelly, indicating that negatively charged glycans influence jelly water balance and contribute to embryonic adaptation to acidity. These results indicate that egg coats can harbor extensive intra-specific variation, probably facilitated in part via strong selection on water balance and glycosylation status of egg jelly coats. These findings shed light on the molecular mechanisms of environmental stress tolerance and adaptive maternal effects.

Keywords Adaptive divergence - Amphibians · Environmental stress · Jelly glycan - Water balance . Zeta potential $\cdot$ Egg coat

4 Department of Environmental Systems Science, ETH Zürich, 8092 Zurich, Switzerland

5 Animal Ecology/Department of Ecology and Genetics, Evolutionary Biology Center, Uppsala University, 75236 Uppsala, Sweden

6 Department of Biology, Washington University in St. Louis, St. Louis, MO 63130, USA 


\section{Introduction}

Environmental stress, defined as a condition that lies outside the optimal conditions for an organism and impairs Darwinian fitness, can have strong ecological consequences and be a powerful evolutionary force at ecological time scales (Hoffmann and Parsons 1997). Given the large spatial heterogeneity in environmental conditions, and the drastic ongoing environmental changes on global and local scales (Millennium Ecosystem Assessment 2005; Hoffmann and Sgrò 2011), it is of key interest how organisms are affected by environmental stress and how they can adapt to them. At early life-stages, organismal responses to stress are often mediated via maternal effects (MEs; i.e. the effects of the mother's phenotype or environment on offspring phenotype or performance; Mousseau and Fox 1998), which can also provide a powerful source of rapid adaptation (Mousseau and Fox 1998; Räsänen and Kruuk 2007). MEs can contribute to adaptive divergence of local populations, allow rapid adaptation, and alter the speed and direction of evolution (Mousseau and Fox 1998; Räsänen and Kruuk 2007). One important-but understudied-source of MEs in numerous taxa, from simple, sexually reproducing multi-cellular organisms to amphibians and mammals, are egg coats, which are maternally derived extracellular structures that surround the organism during early life stages. These structures can have major impacts on fitness, as they both mediate the beginning of life (due to their fundamental role in fertilization) and protect the embryo from a range of environmental hazards (e.g., Wong and Wessel 2006; Hedrick 2008; Menkhorst and Selwood 2008; Berois et al. 2011). They can even facilitate speciation (e.g., Palumbi 2009). Despite these crucial roles of egg coats, however, their role as a target of diversifying natural selection, and the extent of intra-specific variability (i.e. variation within and among individuals and populations) in them, has largely been overlooked.

Environmental stress arising from natural and anthropogenic acidification influences a broad range of aquatic and terrestrial taxa (e.g., Collier et al. 1990; Räsänen and Green 2009; Kroeker et al. 2010; Azevedo et al. 2013). Anthropogenic acidification became an urgent environmental issue upon the industrial revolution (e.g., Seip and Tollan 1978), and rising carbon dioxide $\left(\mathrm{CO}_{2}\right)$ contents in the atmosphere have alerted more recent concern about ocean acidification (Doney et al. 2009; Honisch et al. 2012). An extensive literature reports on the negative effects of acidification on, for example, survival (e.g., Gosner and Black 1957; Findlay et al. 2008), reproduction (e.g., Räsänen et al. 2008; Byrne et al. 2010), calcification (Iglesias-Rodriguez et al. 2008; Anthony et al. 2008) and other physiological processes (Jokiel et al. 2008; Munday et al. 2009; Pespeni et al. 2013) of individual organisms. Whilst often challenging the persistence of natural populations, these negative fitness effects also imply that acidity should cause strong natural selection. In accordance, there is increasing evidence for adaptation to acidity from both freshwater (e.g., Derry and Arnott 2007; Hangartner et al. 2011) and marine (e.g., Lohbeck et al. 2012; Dam 2013; Evans et al. 2013; Pespeni et al. 2013) taxa. The moor frog, Rana arvalis, is one of the best-characterized study systems for adaptation to acidification. $R$. arvalis shows adaptive divergence in embryonic survival, larval traits, as well as maternal investment (Andren et al. 1989; Räsänen et al. 2003a, 2008; Räsänen and Green 2009; Hangartner et al. 2011; EgeaSerrano et al. 2014), providing a well-suited model system to study mechanisms of adaptation to acid stress.

Adaptive divergence in embryonic acid stress tolerance of $R$. arvalis has been previously indicated to arise from maternal effects (Merilä et al. 2004; Persson et al. 2007; Hangartner et al. 2012b), likely mediated via egg coats that surround the developing embryos (Räsänen et al. 2003b). A similar mechanism was proposed for two species of Xenopus (X. laevis and X. gilli) differing in acid tolerance (Picker et al. 1993), possibly suggesting a general mechanism of adaptation to acid stress in amphibians. Amphibian embryos are surrounded by a perivitelline space and different egg coats, which consist of a fertilization envelope and variable numbers of gelatinous outer layers (henceforth called egg jelly) (Hedrick 2008). When amphibian embryos are exposed to acidic conditions, they typically show a "curling defect" (Dunson and Connell 1982; Pierce 1985), whereby embryos develop but become tightly curled within the egg coat and, finally, fail to hatch. The curling defect has been suggested to relate to chemical changes in the egg coats, which become tight and sticky, shrink in size and can change color from transparent to opaque at acidic pH (Dunson and Connell 1982; Pierce 1985; Picker et al. 1993; Räsänen et al. 2003a). However, the molecular underpinnings of the embryonic curling defect and, hence, the mechanistic basis of maternally mediated embryonic adaptation to acid stress remain unexplored. Here, we test the role of chemical alterations of the egg jelly as a mechanism of curling defect and adaptive maternal effects. We hypothesize that the apparent shrinkage of egg coats under acidic conditions is caused by water loss of the egg jelly and examine to what extent this may be related to the glycosylation status of the jelly.

Glycosylation is one of the most important post-translational modifications (PTMs) of proteins (Varki 2011). Amphibian egg jelly consists of highly glycosylated glycoproteins (Lee 1967; Yurewicz et al. 1975; Carroll 1991; Arranz et al. 1997). For example, in the African clawed frog, X. laevis, the jelly consists of more than $60 \%$ of 
Table 1 Descriptive information on three study populations of Rana arvalis used in this study

\begin{tabular}{lllllr}
\hline Population & A & B & C & D & E \\
\hline Stubberud (S) & 5 & $58^{\circ} 46^{\prime} \mathrm{N}, 13^{\circ} 76^{\prime} \mathrm{E}$ & $7.3 \pm 0.2$ & Buffered against acidification due to limestone bedrock & 34,128 \\
Bergsjön (B) & 5 & $58^{\circ} 20^{\prime} \mathrm{N}, 13^{\circ} 48^{\prime} \mathrm{E}$ & $6.1 \pm 0.3$ & Limed since 1989. pH ca. 4.2 due to acidification & $7,221,305$ \\
Tottajärn (T) & 5 & $57^{\circ} 60^{\prime} \mathrm{N}, 12^{\circ} 60^{\prime} \mathrm{E}$ & $4.0 \pm 0.2$ & Natural and human acidification & 462,683 \\
\hline
\end{tabular}

Pond $\mathrm{pH}$ is based on averages of three sites within each pond in April 2008 and April, May and June in 2009. For a map and further details see Hangartner et al. (2011)

$A$ Number of full-sib families used per population; $B$ coordinates $(\mathrm{N}, \mathrm{E}) ; C$ mean $\pm \mathrm{SD}$ pond $\mathrm{pH} ; D$ likely acidification history, $E$ pond size $\left(\mathrm{m}^{3}\right)$

glycans, and many of these are negatively charged (Hedrick and Nishihara 1991; Guerardel et al. 2000). These thick glycan coats are highly hydrated, giving the jelly a considerable capacity to hold water, and this process is correlated with the charge state of glycan molecules (Bansil et al. 1995). Because the charge state is $\mathrm{pH}$-dependent (Mullet et al. 1997), we predict that environmental $\mathrm{pH}$ can affect the charge state of jelly glycans and, consequently, alter jelly water content-resulting in the observed shrinkage of the egg coats and the "curling defect" (Dunson and Connell 1982). In addition, we predict that, if jelly charge status and water retention capacity underlie the maternal effects in embryonic adaptation to acid stress, intra-specific variation in water retention and jelly charge should correlate with embryonic acid tolerance.

To test these hypotheses, we combined three approaches. First, to quantify variation in embryonic acid tolerance among and within populations, we conducted a common garden laboratory experiment using three $R$. arvalis populations (Table 1) known to differ in embryonic acid tolerance (Hangartner et al. 2011). Second, to test how $\mathrm{pH}$ influences water balance of egg jelly, we measured jelly water retention at $\mathrm{pH} 4.0,7.5$ and 10. Third, to test how water balance correlates with charge state of the egg jelly, we measured its zeta potential (Kirby and Hasselbrink 2004a, b). Finally, to test whether jelly water balance and zeta potential vary among and within populations and how it correlates with embryonic acid tolerance, we conducted these measurements on replicate clutches within each of the three populations. This design allowed us to investigate the molecular basis of maternally mediated adaptation to acidity and its consequences for embryonic fitness.

\section{Materials and methods}

\section{Study system}

$R$. arvalis is a widely distributed anuran in the western Palearctic and inhabits a wide range of pHs (Glandt 2006). Three populations (Table 1) breeding in permanent ponds in forested areas in southwestern Sweden, and known to differ in embryonic acid tolerance (details are provided in Hangartner et al. 2011), were used in this study. The $\mathrm{pH}$ in these ponds ranged from roughly $\mathrm{pH} 4$ in the most acid tolerant population (Tottajärn, T) to $\mathrm{pH} 6$ in the intermediately tolerant (Bergsjö, B) and $\mathrm{pH} 7$ in the highly acidsensitive population (Stubberud, $\mathrm{S}$; Table 1). Site $\mathrm{T}$ is situated centrally within a geographic area that has been heavily affected by anthropogenic acidification since the early 1900s (Renberg et al. 1993), whereas site S is situated centrally within a geographic area that has remained unaffected by acid rain due to limestone bedrock (Brunberg and Blomqvist 2001; Hangartner et al. 2011). At both these sites, $\mathrm{pH}$ is relatively stable across years. The site $\mathrm{B}$ is acid-sensitive and has been limed annually since 1989 to counteract acidification (Annica Karlsson, Västra Götaland county board, personal communication). Site B has an average $\mathrm{pH}$ around 6 , but $\mathrm{pH}$ in this lake is highly variable across years (pH 4.5-7.5; Räsänen, personal observation). These patterns indicate selection for increased acid tolerance prior to liming, but potentially fluctuating selection during the last two decades.

During the breeding season of 2013, five clutches were collected in each population from the breeding ponds within ca. $30 \mathrm{~min}$ of egg laying [each site was continuously checked during the sampling night and only freshly laid clutches were collected, see Electronic Supplementary Material (ESM) Fig. S1]. The eggs were immediately transferred to reconstituted soft water (RSW; $48 \mathrm{mg} / \mathrm{l} \mathrm{NaHCO}_{3}$, $30 \mathrm{mg} / \mathrm{l} \mathrm{CaSO} \mathrm{C}_{4} \cdot 2 \mathrm{H}_{2} \mathrm{O}, 61.4 \mathrm{mg} / \mathrm{l} \mathrm{MgSO}_{4} \cdot 7 \mathrm{H}_{2} \mathrm{O}$ and $2 \mathrm{mg} / \mathrm{l}$ $\mathrm{KCl}, \mathrm{pH}$ 7.2-7.6; APHA 1985), maintained at a cool temperature to slow down embryonic development, and transported to the laboratory at Uppsala University within 1 day of collection.

\section{Embryonic acid tolerance test (Experiment 1)}

The embryonic acid tolerance of each clutch was tested using standard procedures (Räsänen et al. 2003a; Hangartner et al. 2011). In short, embryos were reared in a walk-in climate room $\left(\sim 16^{\circ} \mathrm{C}\right)$ with $17 \mathrm{~L}: 7 \mathrm{D}$ photoperiod at two $\mathrm{pH}$ treatments (acid: $\mathrm{pH} 4.0$; neutral: $\mathrm{pH}$ 7.5). RSW was used as the experimental medium (APHA 1985) and 
was prepared in 120-L tanks 2 days prior to use. The $\mathrm{pH}$ in the acid treatment was adjusted with $1 \mathrm{M} \mathrm{H}_{2} \mathrm{SO}_{4}$, whereas the $\mathrm{pH}$ in the neutral treatment was not adjusted (nominal $\mathrm{pH}$ of RSW is 7.2-7.6 when organisms are in the water; APHA 1985). Embryos were placed in the experimental treatments within $3 \mathrm{~h}$ of arrival at the laboratory at Uppsala University and before their mid-cleavage (Gosner 1960).

Experiment 1 was performed as a $2 \times 3 \times 5$ nested randomized design, with two $\mathrm{pH}$ treatments $(\mathrm{pH} 4.0,7.5)$, three populations (T, B, S), and five clutches (i.e. full-sibling families) per population. Each family-pH treatment combination was replicated three times, resulting in a total of 90 experimental units. We chose to use the most acidtolerant, the most acid-sensitive and one intermediate population along our studied acidification gradient (Hangartner et al. 2011; Hangartner et al. 2012a, b) to bracket the typical type of populations and full range of acid tolerances in this area. The replicates were fully randomized over the experimental shelves. Each experimental unit consisted of 20-40 embryos from a given family placed in a plastic vial $(0.9 \mathrm{~L})$, containing $0.5 \mathrm{~L}$ of treatment water. Embryos were reared from fertilization to day 12 (when all surviving embryos should have hatched). Unfertilized eggs (i.e. if no cell division was apparent, eggs were assumed to be unfertilized) were determined at day 3 (when eggs had reached Gosner stage around 12-13) and excluded from the analyses of survival. Fertilization rate was very high, however (almost all eggs were fertilized). Water was changed every third day to maintain appropriate $\mathrm{pH}$ and $\mathrm{pH}$ measured in conjunction of each water change (mean $\pm \mathrm{SD}$ in $\mathrm{pH} 4.0$ treatment: $\mathrm{pH} 4.01 \pm 0.04$ ). The number of hatchlings, and the number of obviously dead embryos or hatchlings, were recorded visually at each water change, but any dead individuals were left untouched. Only final survival (day 12) was used in the statistical analyses. Survival was calculated as number of live hatchlings/total number of fertilized eggs for each experimental unit.

\section{Variation in jelly water content (Experiment 2)}

Variation among clutches and $\mathrm{pH}$ treatments in jelly water content was investigated in Experiment 2 on a separate subset of eggs (but from the same clutches used in Experiment 1). Variation in jelly water content was measured in acid (pH 4.0) and neutral ( $\mathrm{pH} 7.5)$ treatments, as well as in an alkaline ( $\mathrm{pH}$ 10) treatment. These treatments were chosen to test, on the one hand, whether jelly loses water under acidic $\mathrm{pH}$ and, on the other hand, whether jelly absorbs more water under alkaline $\mathrm{pH}$. These patterns would be expected as the charge state of jelly glycans can be influenced by environmental $\mathrm{pH}$ (Mullet et al. 1997). A shift to a different charge state means that the distance among glycan molecules changes: stronger charge-charge repulsions will increase the distance among glycan molecules-thereby resulting in increased ability to retain water, whereas weaker charge-charge repulsions will do the opposite.

Experiment 2 was performed as a $3 \times 3 \times 5$ nested fully randomized design, with three $\mathrm{pH}$ treatments $(\mathrm{pH} 4.0,7.5,10)$, three populations (T, B, S), and five families per population. Each family-pH treatment combination was replicated three times, resulting in a total of 135 experiment units. Each replicate vial had 10 eggs. The $\mathrm{pH}$ in the alkaline treatment was adjusted with $1 \mathrm{M} \mathrm{NaOH}$. Because $\mathrm{pH}$ was less stable in the alkaline treatment (mean \pm SD: $\mathrm{pH} 9.94 \pm 0.11$ ), water in this treatment was changed daily. Otherwise, the general experimental conditions were the same as in Experiment 1. Experiment 2 ended at day 3 (when eggs had reached approximately Gosner stage 12-13), when the eggs were manually de-jellied using watchmaker's forceps (Hedrick and Hardy 1991) and the jelly was collected for water content measurements.

To estimate jelly water content, the fully hydrated jellies from each of the three replicates (per family and treatment), as well as individually marked filter papers (Whatman No. 42), were weighed to the nearest $0.0001 \mathrm{~g}$ (Lab Scales). The jelly samples (i.e. pooled jelly sample of 10 eggs per replicate vial) were then blotted on individually assigned filter paper and oven-dried at $+50{ }^{\circ} \mathrm{C}$ for $4 \mathrm{~h}$ (Lab BenchTop, STATUS). To estimate the amount of dry jelly material (i.e. jelly content without water), jelly dry mass was determined after drying (g) (see ESM for jelly dry mass data). Absolute jelly water content was calculated as the difference in jelly mass $(\mathrm{g})$ before and after drying (Berner and Ingermann 1990). As jelly water content might be influenced by the amount of dry jelly, relative jelly water content (jelly water content per unit of jelly) was calculated as absolute jelly water content/dry jelly mass (g). Given that all clutches were initially maintained at $\mathrm{pH} 7.0$ (i.e. prior to experimental set-up), jelly water loss or gain was calculated as the difference in jelly mass $(\mathrm{g})$ between the neutral and acid (or the neutral and alkaline) treatments.

\section{Zeta potential analyses}

The zeta potential $(\mathrm{mV})$ is the electric potential across the double layer of a charged particle or molecule in solution (McNaught et al. 1997). The zeta potential is directly affected by the net electrical charge of the particle and thus is widely used for quantification of the magnitude of the charge (Kosmulski 2009). In this study, we used the zeta potential as a measure of charge state (negative, neutral or positive) of egg jelly glycans. Negative zeta potential of the jelly sample would indicate negatively charged and thereby acidic glycans in the jelly, whereas a neutral or positive zeta potential would indicate neutral or alkaline glycans.

To determine the zeta potential, a separate subsample of 50 eggs per clutch from a neutral RSW treatment was collected 
manually using watchmaker's forceps and subsequently solubilized in $\mathrm{pH} 8.9$ DeBoers solution containing $45 \mathrm{mM}$ mercaptoethanol (Hedrick and Hardy 1991). The jelly from these eggs was collected at the same time as Experiment 1 was set up (hence before their mid-cleavage). This jelly solution was then adjusted to $\mathrm{pH} 7$ and maintained at $4{ }^{\circ} \mathrm{C}$ for later analyses (Hedrick and Hardy 1991). The zeta potential of each jelly sample was measured using the Zetasizer Nano ZSP (Malvern Instruments). The instrument was calibrated and optimized before each run. Three technical replicates were run on each jelly sample, and the mean of the three replicates was used in statistical analyses. Zeta potential was determined using Malvern Zetasizer Series Software (v.7.02).

\section{Statistical analyses}

The response variables were survival, absolute and relative jelly water content $(\mathrm{g})$ and zeta potential $(\mathrm{mV})$. Survival (number hatched/total embryos/replicate) was analyzed with a generalized linear mixed model (GLMMs) with binomial errors and logit link function in the GLIMMIX procedure of SAS 9.3 (SAS Institute). In the analyses of survival, $\mathrm{pH}$ treatment $(4.0,7.5)$, population $(\mathrm{S}, \mathrm{B}, \mathrm{T})$ and their interaction were used as fixed factors and family (nested within population) and family-treatment interactions as random factors. In subsequent analyses of survival within each of the two $\mathrm{pH}$ treatments, population $(\mathrm{S}, \mathrm{B}, \mathrm{T})$ was used a fixed factor and family (nested within population) as a random factor.
After checking normality and variances, absolute or relative jelly water content was analyzed with type III general linear mixed models in SPSS 20 , with $\mathrm{pH}$ treatment $(4.0,7.5,10)$, population $(\mathrm{S}, \mathrm{B}, \mathrm{T})$ and their interaction as fixed factors, and family (nested within population) and its interaction with $\mathrm{pH}$ treatment as random factors. Relative jelly water content was log-transformed to homogenize variances. As the $\mathrm{pH}$ treatment-family interaction was not significant for either absolute or relative jelly water content, it was excluded from the final models for these two variables. Variation in zeta potential was analyzed based on clutch means (total $n=15$ ) with a one-way analysis of variance (ANOVA) with population as the fixed factor in SPSS 20. Significance of relevant pairwise differences in least square means was tested using Tukey tests.

To gain correlative evidence for relationships among embryonic acid tolerance (survival at $\mathrm{pH} 4.0$ ), jelly water change (i.e. the absolute difference in jelly water content between neutral and acid treatment for a given clutch) and zeta potential, we calculated Pearson correlations in SPSS 20 among clutch means $(n=15)$ of survival, jelly water change and jelly zeta potential.

\section{Results}

\section{Embryonic acid tolerance}

In general, embryonic survival was reduced by up to $60 \%$ at $\mathrm{pH} 4.0$ compared to $\mathrm{pH} 7.5$, as indicated by the significant

Table 2 Generalized linear mixed models of embryonic survival in three $R$. arvalis populations (acid, intermediate and neutral origin) under $\mathrm{pH}$ 4.0 and 7.5 treatments in the (a) full model and (b) by $\mathrm{pH}$ treatment

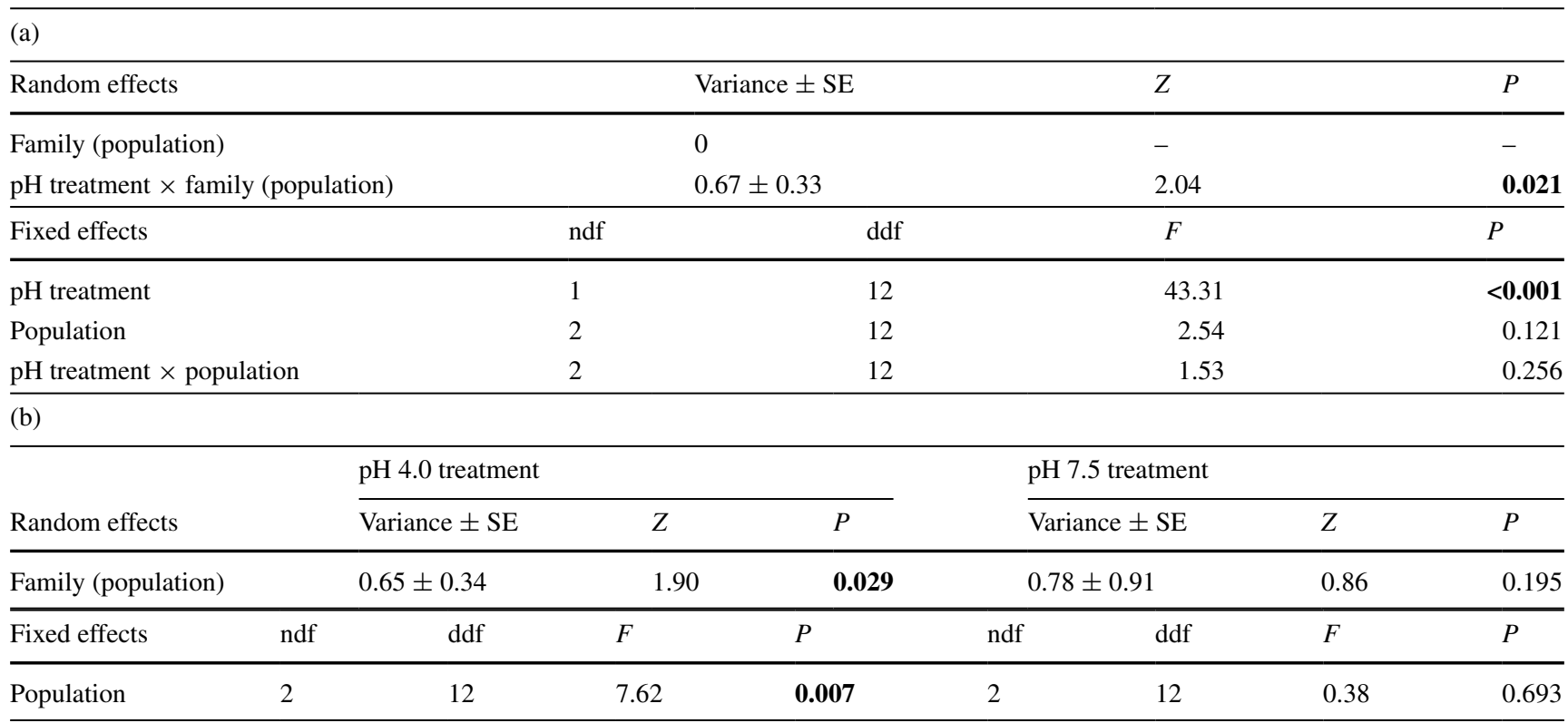

Significant effects $(P<0.05)$ are highlighted in bold 


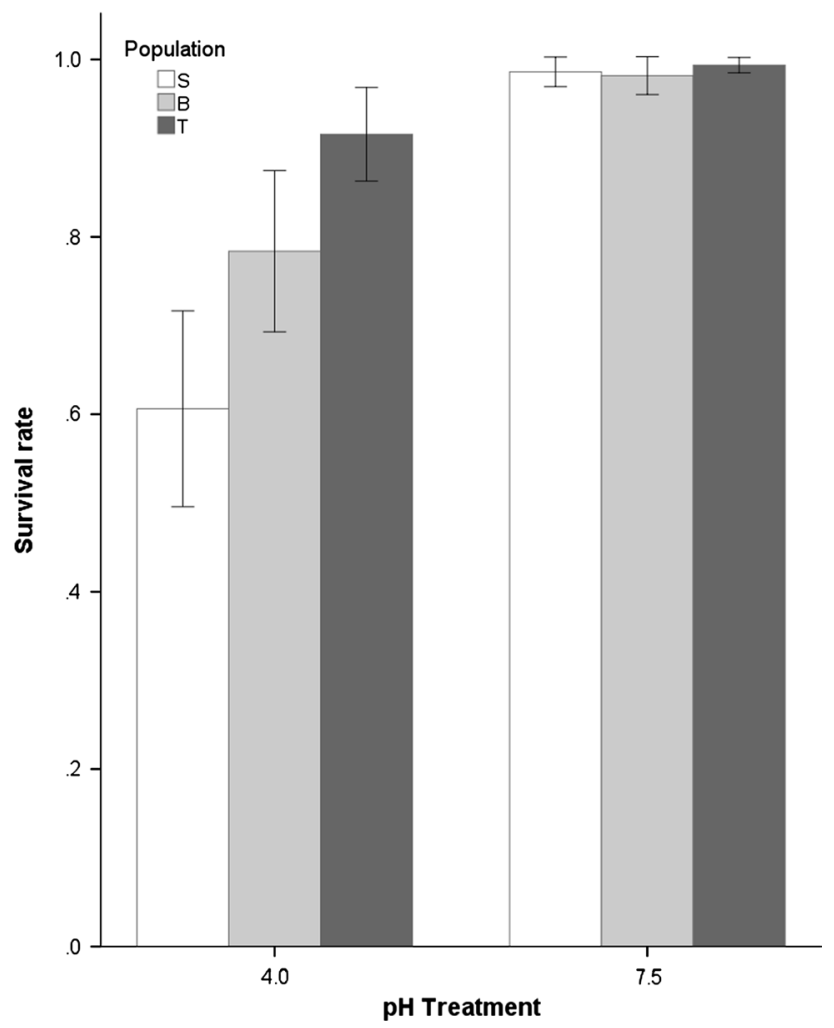

Fig. 1 Survival rate (mean $\pm \mathrm{SE})$ of $R$. arvalis embryos $(n=90)$ in three populations $(\mathrm{S}, \mathrm{B}, \mathrm{T})$ at two $\mathrm{pH}$ treatments $(\mathrm{pH} 4.0$ and 7.5$)$

pH treatment main effect (Fig. 1; Table 2). The pH treatment $\times$ population interaction was not significant (Table 2) in this study. However, a significant $\mathrm{pH}$ treatment $\times$ family interaction indicated strong family level variation within populations in $\mathrm{pH}$ tolerance (Table 2). To investigate the nature of the $\mathrm{pH} \times$ family interactions, we subsequently analyzed the data within each of the $\mathrm{pH}$ treatments. At $\mathrm{pH}$ 7.5 , survival was very high (ranging from 92.8 to $100 \%$ ) in all clutches and there was no significant family or population level variation (Table 2). At $\mathrm{pH} 4.0$, a significant family effect indicated family level variation in embryonic acid tolerance within populations (Table 2). In addition, a significant population main effect (Table 2) arose as embryos from population $\mathrm{T}$ had significantly higher survival than embryos from population $\mathrm{S}$ (Tukey test, $P=0.005$ ), while survival of embryos from the population $\mathrm{B}$ was intermediate and did not differ significantly from either $\mathrm{T}$ or $\mathrm{S}$ population (Tukey test, both $P>0.1$ ) (Fig. 1; Table 2).

\section{Population and $\mathrm{pH}$ treatment variation in jelly water content}

Absolute jelly water content differed significantly among the three pH treatments (Fig. 2a; Table 3): jelly contained less water in the acid treatment than in the neutral treatment (pairwise Tukey test: $P<0.001$; Fig. 2a), indicating that jelly water was lost in the acid treatment. Likewise, in absolute terms, jelly contained significantly more water in the alkaline treatment, indicating that it absorbed more water in the alkaline treatment than in the neutral treatment (pairwise Tukey test: $P<0.001$; Fig. 2a). These patterns were paralleled by visual inspection that indicated that the jelly became compact and less pliable in the acid treatment, while it expanded in the alkaline environment to the extent
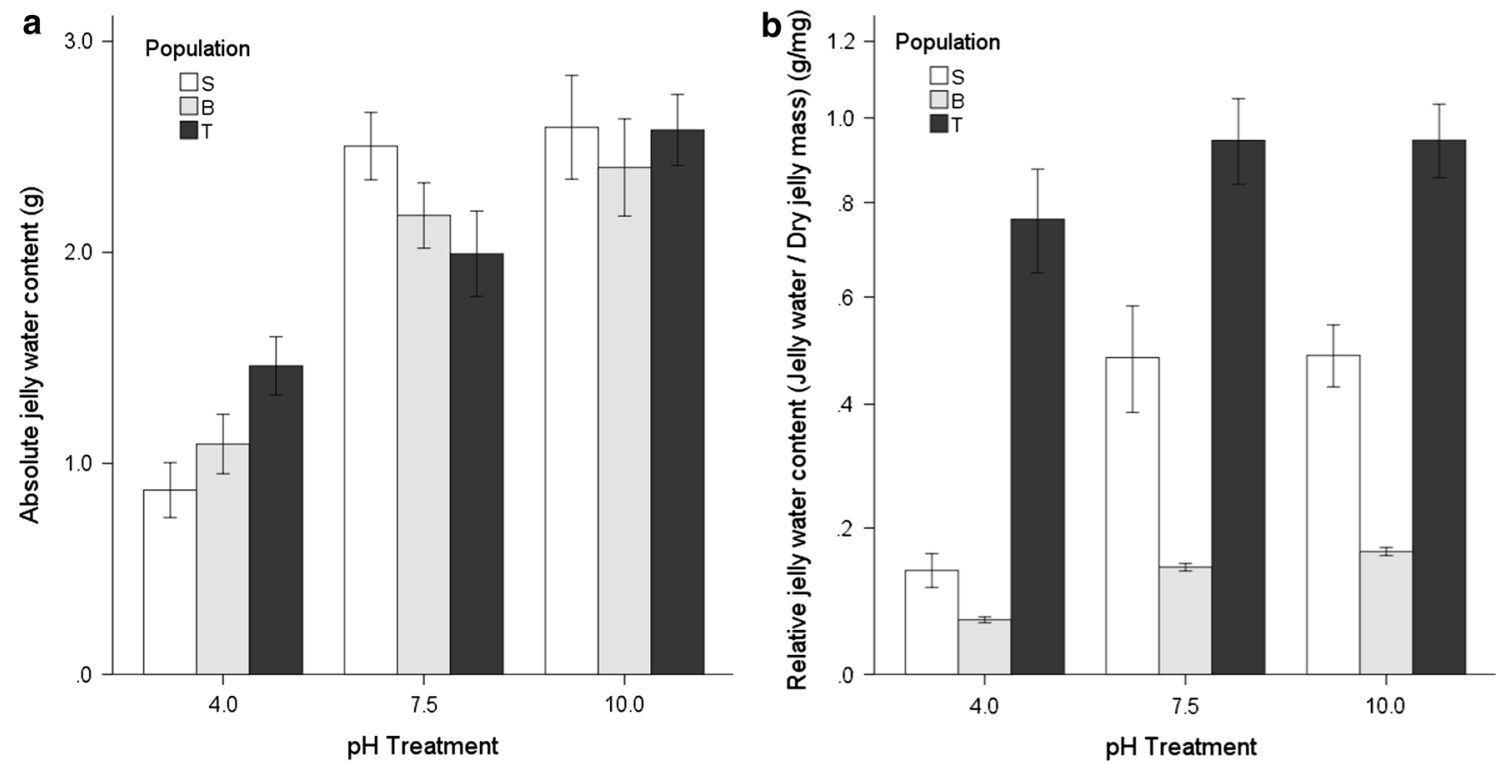

Fig. 2 Jelly water content $(n=90)$ in three $R$. arvalis populations $(\mathrm{S}, \mathrm{B}, \mathrm{T})$ at three $\mathrm{pH}$ treatments $(\mathrm{pH} 4.0,7.5,10)$. The figures represent mean \pm SEs of $\mathbf{a}$ absolute jelly water content, and $\mathbf{b}$ relative jelly water content (corrected for jelly dry mass) 
Table 3 General linear mixed models of absolute and relative (corrected for jelly dry mass of 10 eggs/replicate) jelly water content in three $R$. arvalis populations (acid, intermediate and neutral origin) under $\mathrm{pH} 4.0,7.5$ and 10 treatments

\begin{tabular}{|c|c|c|c|c|c|c|c|c|c|c|}
\hline & \multicolumn{5}{|c|}{ Absolute jelly water content } & \multicolumn{5}{|c|}{ Relative jelly water content } \\
\hline & Type III SS & $d f$ & Mean square & $F$ & $P$ & Type III SS & $d f$ & Mean square & $F$ & $P$ \\
\hline \multicolumn{11}{|l|}{ Random effects } \\
\hline Family (population) & 1.49 & 12 & 0.12 & 1.05 & 0.412 & 0.48 & 12 & 0.04 & 0.80 & 0.654 \\
\hline \multicolumn{11}{|l|}{ Fixed effects } \\
\hline $\mathrm{pH}$ treatment & 47.46 & 2 & 23.73 & 199.61 & $<0.001$ & 3.48 & 2 & 1.74 & 34.69 & $<0.001$ \\
\hline Population & 0.40 & 2 & 0.20 & 1.61 & 0.241 & 17.55 & 2 & 8.77 & 219.86 & $<0.001$ \\
\hline Population $\times \mathrm{pH}$ treatment & 4.63 & 4 & 1.16 & 9.73 & $<0.001$ & 1.50 & 4 & 0.38 & 7.48 & $<0.001$ \\
\hline
\end{tabular}

Significant effects $(P<0.05)$ are highlighted in bold

of showing more flabby structure (L. Shu, personal observation). Moreover, a significant $\mathrm{pH}$ treatment $\times$ population interaction indicated that populations differed in water content at different $\mathrm{pH}$. At $\mathrm{pH} 4.0$, jelly from population $\mathrm{T}$ had lost least and jelly from population $\mathrm{S}$ most water, while jelly from population B was intermediate in jelly water loss (Fig. 2a; Table 3).

Also in terms of relative jelly water content (Fig. 2b), acid treatment caused jelly water loss compared to the neutral treatment (pairwise Tukey tests, $P<0.001$; Fig. 2b). However, the difference between the alkaline treatment and neutral treatment was not significant (Tukey test, $P=0.920$; Fig. 2b). A significant population main effect arose as the jelly from population $\mathrm{T}$ had significantly higher relative jelly water content than jelly in the other two populations at all $\mathrm{pH}$ treatments (pairwise Tukey tests, both $P<0.001$ ), and jelly from population B had a lower relative water content than jelly from population $\mathrm{S}$ (Tukey test, $P<0.001$; Fig. 2b; Table 3 ). This indicated that populations overall differed in overall ability to absorb water. In accordance with the absolute jelly water content analysis, a significant $\mathrm{pH}$ treatment $\times$ population interaction showed that populations differed in relative water loss in the acid treatment, whereby $\mathrm{T}$ population lost least water at $\mathrm{pH} 4.0$ (Fig. 2b; Table 3).

\section{Variation in zeta potential of jelly}

The zeta potential of all clutches was negative (range -12.600 to $-32.533 \mathrm{mV}$; Fig. 3), indicating that the jelly consisted of negatively charged components. Moreover, the distribution of zeta potential in all clutches had a unique peak (Fig. 3a), indicating that egg jelly glycans assemble to form a stable homogenized structure with a negative surface charge. Zeta potential differed among populations ( $F_{2,12}=4.43, P=0.036$; Fig. $3 \mathrm{~b}$ ), with jelly of population $\mathrm{T}$ being more negatively charged than jelly of population $\mathrm{S}$ (Tukey test, $P=0.031$; Fig. $3 \mathrm{~b}$ ). There was no significant difference between the intermediate population $\mathrm{B}$ and the other two populations (T: $P=0.534$; and S: $P=0.196$; Fig. 3b).

\section{Correlations between jelly water content, acid tolerance and zeta potential}

In general, embryonic acid tolerance was negatively correlated with acidity induced jelly water loss (Fig. 4a; $r=-0.807, P<0.0001 ; n=15)$, suggesting that the ability to retain water in the jelly at acidic conditions has adaptive value. Moreover, zeta potential was negatively correlated with embryonic acid tolerance (Fig. 4b; $r=-0.653$, $P<0.009, n=15)$, and positively correlated with acidityinduced jelly water loss (Fig. 4c; $r=0.664, P<0.009$, $n=15)$, suggesting that negatively charged glycans influence jelly water content and, hence, contribute to embryonic acid stress tolerance.

\section{Discussion}

Maternal effects (MEs) can be an important means of adaptation to environmental stress (Räsänen and Kruuk 2007). At early life-stages, MEs often arise via egg coats, which, however, have rarely been directly studied in this context. We found that embryonic survival (hatching rate) correlated with the extent of water loss from the gelatinous egg coats (jelly) at acidic conditions, and that jelly from an acid-adapted population retained more water at $\mathrm{pH} 4.0$ than jelly from the two other populations. Moreover, the significant correlations between embryonic survival, jelly water loss and zeta potential (indicative of surface charge) of the jelly suggest that maternal effects derived from glycosylation status of the egg coats may play an essential role in embryonic adaptation to acidity. These results shed light on the underlying sources of variation in embryonic stress tolerance both among and within populations (Räsänen et al. 2003a; Hangartner et al. 2011). Our study is the first to show that acidity causes severe water loss of egg jelly 
Fig. 3 Zeta potential $(n=15)$ of jelly as a distribution from one representative jelly sample and $\mathbf{b}$ boxplot of egg jelly zeta potential in each of three $R$. arvalis populations $(\mathrm{S}, \mathrm{B}, \mathrm{T})$. All samples had a single peak (details not shown), which indicates that egg jelly glycans assemble to form a stable homogenized structure with a negative surface charge. In (b), the boxes indicate the interquartile range ( 25 and $75 \%$ ) and the thick line within the box represents the median of five clutches/populations. Whiskers represent the minimum or maximum values a

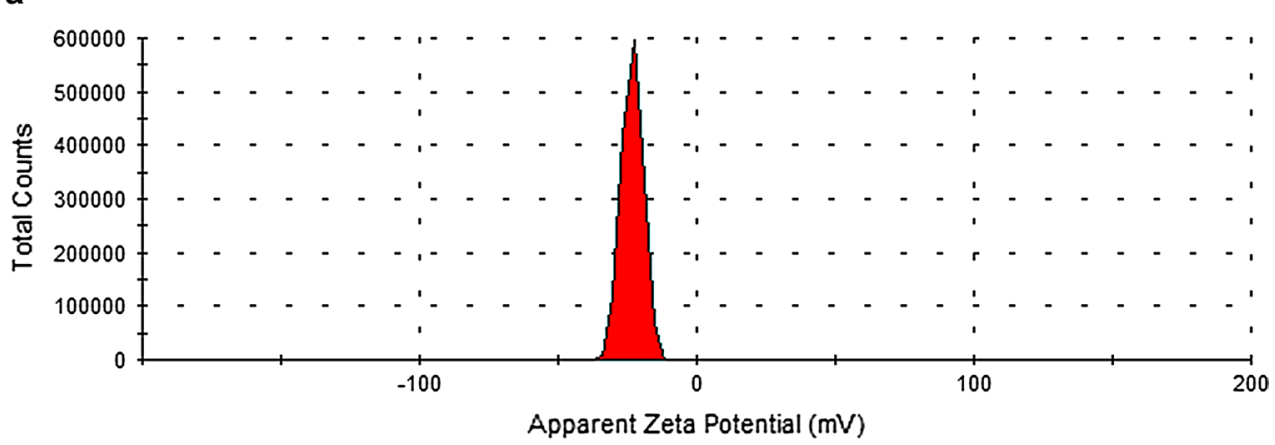

b

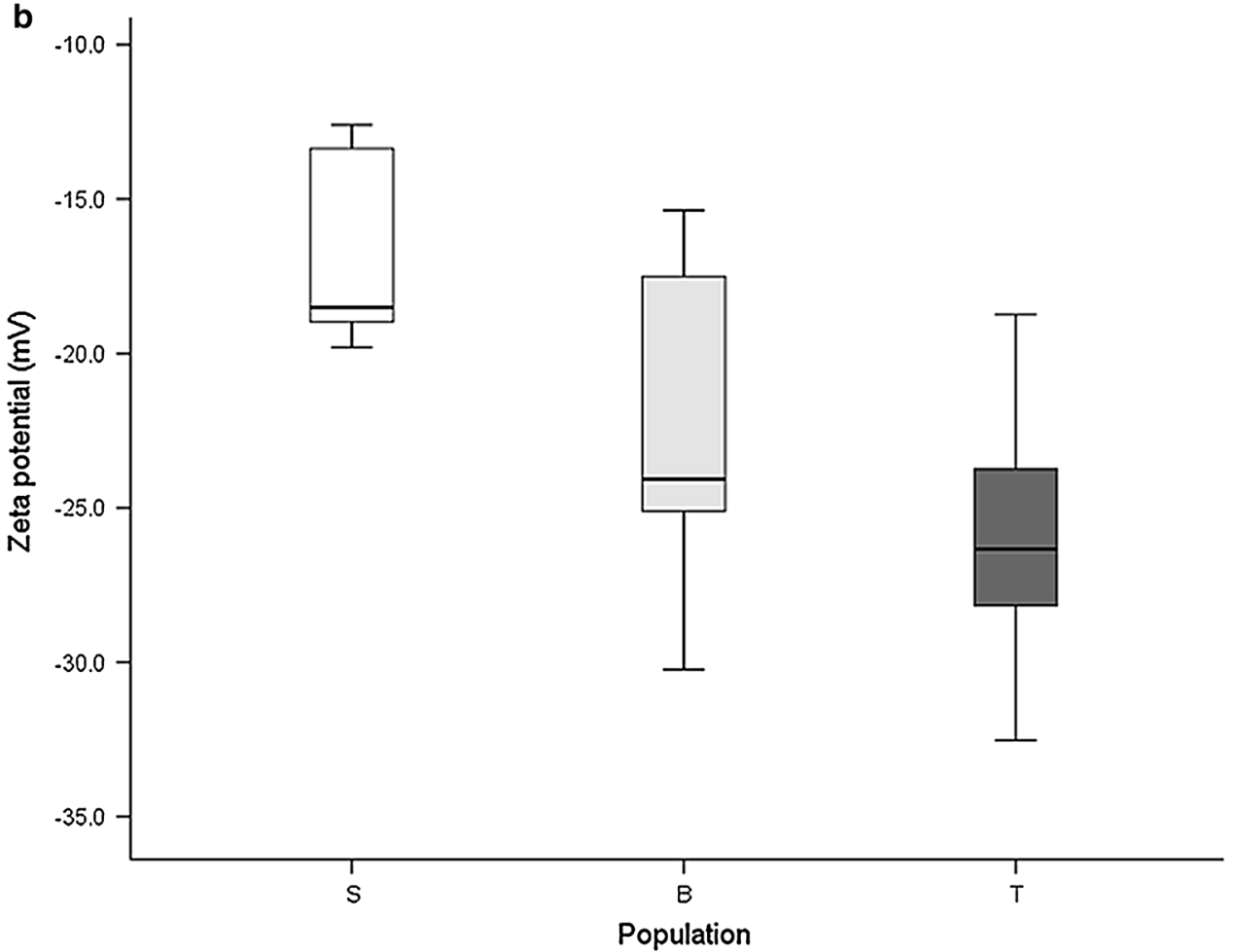

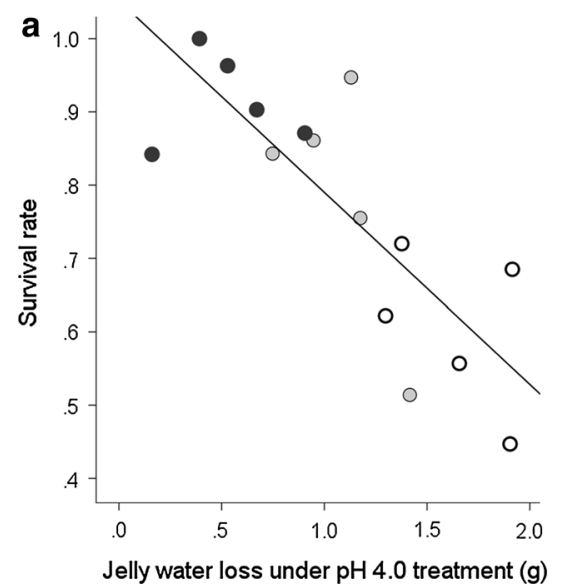
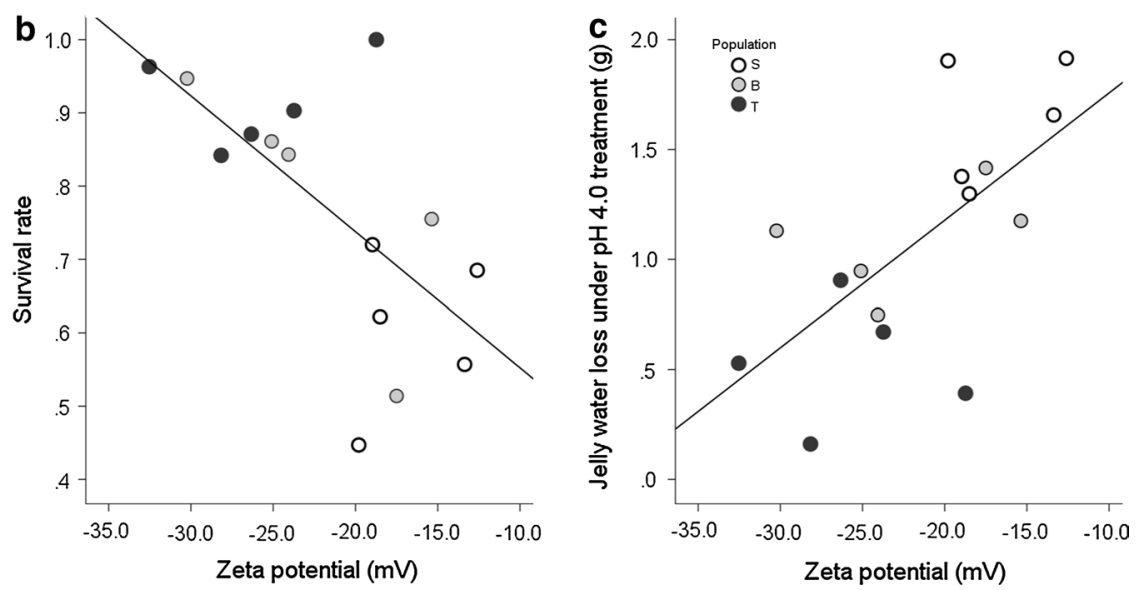

Fig. 4 Scatterplot of clutch means $(n=15)$ of a jelly water loss and embryonic acid tolerance (survival at pH 4.0 ), b zeta potential and embryonic acid tolerance, and $\mathbf{c}$ zeta potential and jelly water loss across three $R$. arvalis populations $(\mathrm{S}, \mathrm{B}, \mathrm{T})$ 
in amphibians, and provides first evidence for intra-specific adaptive divergence in jelly water balance. In the following, we discuss the possible role of environmental acidification as a selective force on jelly water content, the molecular basis of this process, and propose a "water balance model" for jelly responses to $\mathrm{pH}$.

\section{Acidification as an environmental stressor and selective force on jelly water content}

Many amphibians, as well as, for example, gastropod molluscs, sea urchins and many fish species (Menkhorst and Selwood 2008), have thick gelatinous egg coats (i.e. jelly). These jelly coats consist of variable numbers of thin gelatinous layers, which take up water, swell upon their first contact with it (Salthe 1963). The high capacity of jelly to absorb water is of crucial importance for the reproducing female and the eggs: it allows for smaller space (and hence more eggs) whilst the eggs are still inside the mother, yet enables the subsequent swelling and ecological functions, such as protecting the embryo from a range of environmental hazards (e.g., dehydration, pathogens, pollution or UV-radiation; Menkhorst and Selwood 2008). Hence, any environmental factor that substantially disrupts jelly water balance, and, as a consequence, embryonic fitness, may cause strong selection based on jelly water balance-either by influencing jelly water uptake capacity and/or by affecting jelly water loss.

We here show that acidic $\mathrm{pH}$ reduces embryonic survival and induces jelly water loss in $R$. arvalis and that jelly of an acid-tolerant $(\mathrm{T})$ population lost less water under acidic conditions than jelly of an acid-sensitive (S) population, whereas the extent of water loss was intermediate in the population (B) with intermediate acid tolerance. Moreover, across all clutches, we found correlative evidence that embryonic acid stress tolerance increased as jelly water loss decreased.

Our results have the following main implications in relation to acid stress from the ecological and evolutionary points of view. From an ecological point of view, the results suggest that the commonly observed "curling defect", which has been put forward as the main cause behind reduced embryonic survival under acidic conditions in amphibians (reviewed in Räsänen and Green 2009), arises at least in part from jelly water loss: as acidic $\mathrm{pH}$ induces water loss, the jelly becomes more tight and sticky, and, consequently, traps the embryo inside. Jelly water loss may also disturb the water balance and gas exchange of embryos, further reducing embryonic survival (Seymour 1994; Herrler and Beier 2000).

Intriguingly, from an evolutionary point of view, our results suggest that adaptation to acidification in $R$. arvalis may occur via jelly water balance. Adjustments of jelly water balance may therefore provide a key adaptive mechanism behind the egg coat-related maternal effects, facilitating adaptive divergence in embryonic acid tolerance in amphibians (Räsänen et al. 2003a; Hangartner et al. 2011; reviewed in Räsänen and Green 2009). However, for logistical reasons, we used only the two most extreme and one intermediate population from an acidification gradient, and, to further validate the generality of our findings, more populations across $\mathrm{pH}$ gradients should be examined. In addition, such adaptive mechanisms are yet to be explored in other taxa, such as those exposed to ocean acidification (Kroeker et al. 2010; Pespeni et al. 2013).

In addition to affecting the egg coats themselves, it is also possible that egg coat-mediated effects of acidity on embryos are in part mediated via the perivitelline space (PS) that surrounds the embryo. The PS also shrinks under acid stress (Dunson and Connell 1982; Pierce 1985; Picker et al. 1993). The width of the PS is driven by osmotic water potential and, hence, anything (acidic $\mathrm{pH}$ or other solutes) that reduces water potential in the environment will make the PS smaller, which can have deleterious effects on embryos (Gosner and Black 1957; Pierce 1985). Our study was not designed to investigate impacts of $\mathrm{pH}$ on the PS, but it would be interesting to further investigate possible synergistic effects between the water balance of the PS and the jelly coat under varying $\mathrm{pH}$ conditions.

\section{Role of extracellular glycan diversity in adaptive evolution}

All cells are covered by glycan coats, which are essential for numerous biological processes, such as cell communication and pathogen defense (Gagneux and Varki 1999). These extracellular glycans show great diversity and are highly dynamic across taxa (Varki 2011). However, although glycans are often a key component of egg coats, and egg coats have fundamental biological functions from fertilization to protection from environmental hazards (Menkhorst and Selwood 2008; Shu 2014), to date next to nothing is known about intra-specific glycan variation of egg coats, or the functional and evolutionary consequences of this diversity. Most studies to date have focused on quantifying glycan compositional variation among taxa (e.g., Coppin et al. 1999). In a rare study, intra-specific polymorphism, equivalent of human blood groups, was found in the macromolecular composition of the egg jelly in $X$. laevis - but the functional consequences remained unclear (Guerardel et al. 2000).

Our study is among the first to quantify a molecular component of intra-specific jelly variation (here related to zeta potential). In doing so, we have taken a step closer to link molecular variation of egg coats with its fitness consequences. In addition to the clear differences in jelly water 


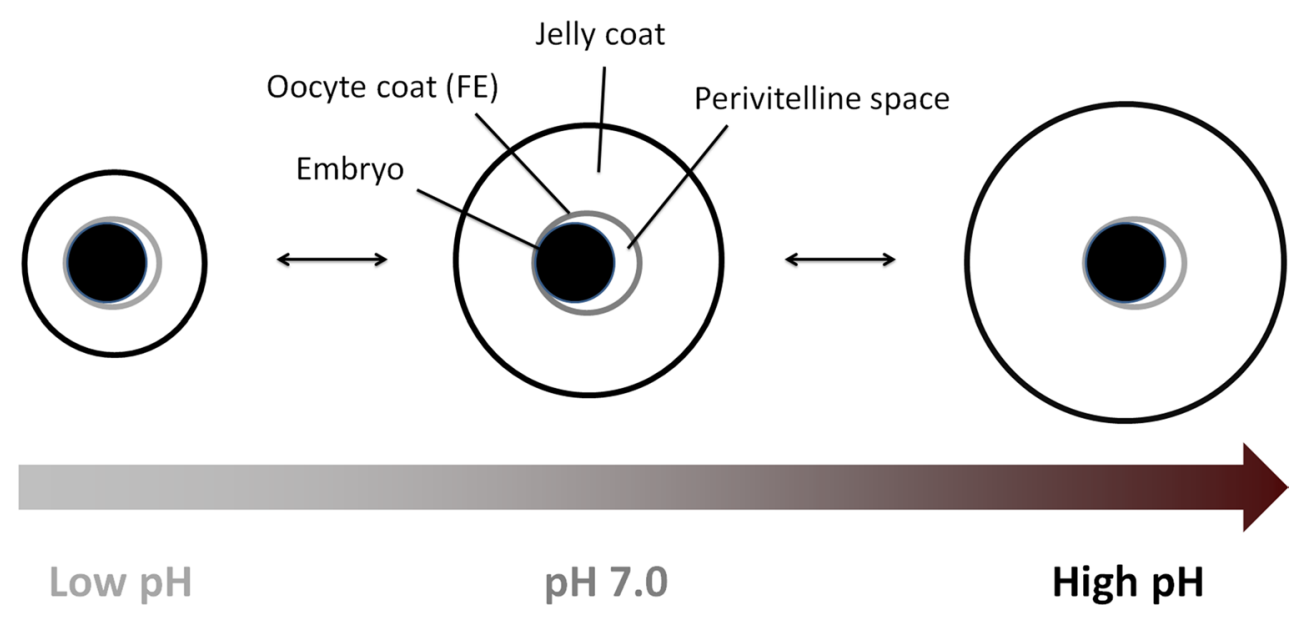

Fig. 5 A schematic presentation of the basic structure of an amphibian egg and the proposed "pH-jelly water balance" model of jelly coats. The embryo is surrounded by a perivitelline space, an oocyte coat [called the fertilization envelope (FE) upon fertilization] and variable numbers of gelatinous layers (so-called jelly coat). According to the "pH-jelly water balance" model, the jelly coat absorbs less and/ or loses more water at acidic $\mathrm{pH}$, while absorbing more water at alka-

content at different $\mathrm{pHs}$ and in different populations, we also found that $R$. arvalis jelly is negatively charged, indicating that it primarily consists of acidic glycans. Intriguingly, our analyses of zeta potential further indicate that egg jelly coats in the acid tolerant population (T) have a higher proportion of acidic glycans (as indicated by the more negative charge status of jelly), which correlates with a higher ability to retain more water per jelly unit, compared to the more acid-sensitive $\mathrm{S}$ and B populations. Across all experimental clutches, the jelly charge status correlated with higher embryonic fitness (survival) under acidic conditions, indicating that intra-specific extracellular glycan diversity (e.g., amount or type of acidic glycans) may undergo adaptive evolution in response to environmental stress, such as acidification. Several different pathways may influence glycan variation, but to what extent this variation reflects environmentally induced plasticity or variation in gene expression or strict genetic responses (Gagneux and Varki 1999; Varki 2011) is currently unclear. Hence, future studies should quantify glycan composition and the genetic basis of this variation to gain insight into the molecular basis of egg coat-mediated maternal effects.

\section{General "pH-jelly water balance" model}

Although the swelling of egg jelly in water is a well-known phenomenon, surprisingly few studies have explored the underlying mechanism of water uptake and how jelly water balance is influenced by environmental factors. With regard to amphibians, a study on the salamander Ambystoma macrodactylum indicated that sialic acid may play a role in jelly line $\mathrm{pH}$ compared to neutral $\mathrm{pH}$ conditions. This water uptake/retention is expected to be mediated by glycans that are the major component of the jelly coat glycoproteins. The perivitelline space should shrink both under acidic and alkaline $\mathrm{pH}$ because of the solutes in the environment (i.e. due to differences in water potential). However, this component remains to be experimentally tested

water retention (Berner and Ingermann 1990). However, mass spectrometric studies found no evidence of sialic acid in jelly of $R$. arvalis (Coppin et al. 1999), which we confirmed for our study populations using a sialic acid detection kit (data not shown). Thus, other mechanisms are needed for variation in $R$. arvalis water balance in relation to $\mathrm{pH}$.

With regard to $\mathrm{pH}$, we propose a general " $\mathrm{pH}$-jelly water balance" model, whereby jelly shrinks at acidic $\mathrm{pH}$ due to water loss and expands at neutral or alkaline $\mathrm{pHs}$ due to water uptake (Fig. 5). We suggest that this effect arises because the surface charge of the glycans in the egg jelly is affected by water $\mathrm{pH}$ (Mullet et al. 1997): compared to neutral conditions, acidic $\mathrm{pH}$ (in our case $\mathrm{pH} 4.0$ ) reduces net negative charge by protonating acidic moieties, which results in a weaker electrostatic repulsion, and therefore reduces the capacity for retaining water. Alkaline $\mathrm{pH}$ on the other hand has the opposite effect by increasing the net negative charge and, thus, causing a stronger charge-charge repulsion (Mullet et al. 1997; Patil et al. 2007). These hypotheses were supported by our jelly water content measurement under different $\mathrm{pH}$, and the zeta potential measurements. We believe this model is extendable to other aquatic species that have gelatinous structures surrounding their embryos, such as insects, mollusks, sea urchins, fish, and other amphibians (Menkhorst and Selwood 2008). Finally, given that jelly water balance can have strong effects on embryonic fitness (as shown here), environmental stressors that affect jelly water balance (e.g., acidification, salinity or temporally drying breeding sites), may induce strong selection on jelly water balance - and hence glycan diversity-in aquatic species that have gelatinous egg coats. 


\section{Conclusions}

Our study revealed that acid stress causes severe water loss of egg jelly and likely imposes strong selection on water balance of egg jelly in amphibians due to subsequently reduced embryonic hatching success. We suggest that a "pH-jelly water balance" model, mediated via intra-specific glycan variability, may help explaining the molecular basis of embryonic adaptation to acid stress and egg coat-mediated adaptive maternal effects.

Author contribution statement LS had the initial idea and LS and KR conceived and planned the study. LS performed the experiments. AL and MS participated in the conceptual and technical development and discussion of the experiments. All authors discussed the results and commented on the manuscript. All authors read and approved the final manuscript.

Acknowledgments We thank Beatrice Lindgren for invaluable help with the field and laboratory work, Baptiste Pasteur for help in collecting the frogs, and Yang Yue for help with the zeta potential measurement. The experiments were conducted under permissions from the Västra Götaland county board and the Ethical committee for animal experiments in Uppsala County. This study was supported by Swiss National Science foundation (to K.R.).

Conflict of interest The authors declare that they have no competing interests.

\section{References}

Andren C, Marden M, Nilsson G (1989) Tolerance to low pH in a population of moor frogs, Rana arvalis, from an acid and a neutral environment: a possible case of rapid evolutionary response to acidification. Oikos 56:215-223

Anthony KRN, Kline DI, Diaz-Pulido G, Dove S, Hoegh-Guldberg O (2008) Ocean acidification causes bleaching and productivity loss in coral reef builders. Proc Natl Acad Sci USA 105:17442-17446

APHA (1985) Standard methods for the examination of water and wastewater, vol 16. American Public Health Association, Washington, DC

Arranz SE, Albertali IE, Cabada MO (1997) Bufo arenarum egg jelly coat: purification and characterization of two highly glycosylated proteins. Biochem J 323:307-312

Azevedo LB, van Zelm R, Hendriks AJ, Bobbink R, Huijbregts MA (2013) Global assessment of the effects of terrestrial acidification on plant species richness. Environ Pollut 174:10-15

Bansil R, Stanley HE, Lamont JT (1995) Mucin biophysics. Annu Rev Physiol 57:635-657

Berner NJ, Ingermann RL (1990) Role of sialic acid in exogenous protein accumulation and water retention by the egg jelly of the Salamander Ambystoma macrcbdactylum. J Exp Zool 256:38-43

Berois N, Arezo MJ, Papa NG (2011) Gamete interactions in teleost fish: the egg envelope. Basic studies and perspectives as environmental biomonitor. Biol Res 44:119-124
Brunberg AK, Blomqvist P (2001) Quantification of anthropogenic threats to lakes in a lowland county of central Sweden. Ambio 30:127-134

Byrne M, Soars N, Selvakumaraswamy P, Dworjanyn SA, Davis AR (2010) Sea urchin fertilization in a warm, acidified and high $\mathrm{pCO}(2)$ ocean across a range of sperm densities. Mar Environ Res 69:234-239

Carroll EJ (1991) Structure and macromolecular-composition of the egg and embryo jelly coats of the anuran Lepidobatrachus laevis. Dev Growth Differ 33:37-43

Collier KJ, Ball OJ, Graesser AK, Main MR, Winterbourn MJ (1990) Do organic and anthropogenic acidity have similar effects on aquatic fauna? Oikos 59:33-38

Coppin A, Maes E, Flahaut C, Coddeville B, Strecker G (1999) Acquisition of species-specific O-linked carbohydrate chains from oviducal mucins in Rana arvalis - a case study. FEBS J 266:370-382

Dam HG (2013) Evolutionary adaptation of marine zooplankton to global change. Annu Rev Mar Sci 5:349-370

Derry AM, Arnott SE (2007) Adaptive reversals in acid tolerance in copepods from lakes recovering from historical stress. Ecol Appl 17:1116-1126

Doney SC, Fabry VJ, Feely RA, Kleypas JA (2009) Ocean acidification: the other $\mathrm{CO}_{2}$ problem. Annu Rev Mar Sci 1:169-192

Dunson WA, Connell J (1982) Specific-inhibition of hatching in amphibian embryos by low pH. J Herpetol 16:314-316

Egea-Serrano A, Hangartner S, Laurila A, Räsänen K (2014) Multifarious selection through environmental change: acidity and predator-mediated adaptive divergence in the moor frog (Rana arvalis). Proc R Soc Lond B 281:20133266

Evans TG, Chan F, Menge BA, Hofmann GE (2013) Transcriptomic responses to ocean acidification in larval sea urchins from a naturally variable $\mathrm{pH}$ environment. Mol Ecol 22:1609-1625

Findlay HS, Kendall MA, Spicer JI, Turley C, Widdicombe S (2008) Novel microcosm system for investigating the effects of elevated carbon dioxide and temperature on intertidal organisms. Aquat Biol 3:51-62

Gagneux P, Varki A (1999) Evolutionary considerations in relating oligosaccharide diversity to biological function. Glycobiology 9:747-755

Glandt D (2006) Der Moorfrosch—Einheit und Vielfalt einer Braunfroschart. Laurenti, Bielefeld

Gosner KL (1960) A simplified table for staging anuran embryos and larvae with notes on identification. Herpetologica 16:183-190

Gosner KL, Black IH (1957) The effects of acidity on the development and hatching of New-Jersey frogs. Ecology 38:256-262

Guerardel Y, Kol O, Maes E, Lefebvre T, Boilly B, Davril M, Strecker G (2000) O-glycan variability of egg-jelly mucins from Xenopus laevis: characterization of four phenotypes that differ by the terminal glycosylation of their mucins. Biochem J 352:449-463

Hangartner S, Laurila A, Räsänen K (2011) Adaptive divergence of the moor frog (Rana arvalis) along an acidification gradient. BMC Evol Biol 11:366

Hangartner S, Laurila A, Räsänen K (2012a) Adaptive divergence in moor frog (Rana Arvalis) populations along an acidification gradient: inferences from Qst-Fst correlations. Evolution 66:867-881

Hangartner S, Laurila A, Räsänen K (2012b) The quantitative genetic basis of adaptive divergence in the moor frog (Rana arvalis) and its implications for gene flow. J Evol Biol 25:1587-1599

Hedrick JL (2008) Anuran and pig egg zona pellucida glycoproteins in fertilization and early development. Int J Dev Biol 52:683-701

Hedrick J, Hardy D (1991) Chapter 12 Isolation of extracellular matrix structures from Xenopus laevis oocytes, eggs, and embryos. In: Kay BK, Peng HB (eds) Xenopus laevis: practical uses in cell and molecular biology, vol. 36. Acedemic, London 36 , pp 231-247 
Hedrick JL, Nishihara T (1991) Structure and function of the extracellular matrix of anuran eggs. J Electron Micr Tech 17:319-335

Herrler A, Beier HM (2000) Early embryonic coats: morphology, function, practical applications-an overview. Cells Tissues Organs 166:233-246

Hoffmann AA, Parsons PA (1997) Extreme environmental change and evolution. Cambridge University Press, Cambridge

Hoffmann AA, Sgrò CM (2011) Climate change and evolutionary adaptation. Nature 470:479-485

Honisch B, Ridgwell A, Schmidt DN, Thomas E, Gibbs SJ et al (2012) The geological record of ocean acidification. Science 335:1058-1063

Iglesias-Rodriguez MD, Halloran PR, Rickaby RE, Hall IR et al (2008) Phytoplankton calcification in a high $\mathrm{CO}_{2}$ world. Science 320:336-340

Jokiel PL, Rodgers KS, Kuffner IB, Andersson AJ, Cox EF, Mackenzie FT (2008) Ocean acidification and calcifying reef organisms: a mesocosm investigation. Coral Reefs 27:473-483

Kirby BJ, Hasselbrink EF (2004a) Zeta potential of microfluidic substrates: 1 . Theory, experimental techniques, and effects on separations. Electrophoresis 25:187-202

Kirby BJ, Hasselbrink EF (2004b) Zeta potential of microfluidic substrates: 2. Data for polymers. Electrophoresis 25:203-213

Kosmulski M (2009) Surface charging and points of zero charge. CRC, Boca Raton

Kroeker KJ, Kordas RL, Crim RN, Singh GG (2010) Meta-analysis reveals negative yet variable effects of ocean acidification on marine organisms. Ecol Lett 13:1419-1434

Lee PA (1967) Studies of frog oviducal jelly secretion 2. Cytology of secretory cycle. J Exp Zool 166:107-119

Lohbeck KT, Riebesell U, Reusch TBH (2012) Adaptive evolution of a key phytoplankton species to ocean acidification. Nat Geosci 5:346-351

McNaught AD, Wilkinson A, International Union of Pure and Applied Chemistry (1997) Compendium of chemical terminology: IUPAC recommendations, 2nd edn. Blackwell, Oxford

Menkhorst E, Selwood L (2008) Vertebrate extracellular preovulatory and postovulatory egg coats. Biol Reprod 79:790-797

Merilä J, Söderman F, O'Hara R, Räsänen K, Laurila A (2004) Local adaptation and genetics of acid-stress tolerance in the moor frog, Rana arvalis. Conserv Genet 5:513-527

Millennium Ecosystem Assessment (2005) Ecosystems and human well-being. Synthesis Island Press, Washington, DC

Mousseau TA, Fox CW (eds) (1998) Maternal effects as adaptations. Oxford University Press, New York

Mullet M, Fievet P, Reggiani JC, Pagetti J (1997) Surface electrochemical properties of mixed oxide ceramic membranes: zetapotential and surface charge density. J Membr Sci 123:255-265

Munday PL, Dixson DL, Donelson JM, Jones GP, Pratchett MS et al (2009) Ocean acidification impairs olfactory discrimination and homing ability of a marine fish. Proc Natl Acad Sci USA 106:1848-1852
Palumbi SR (2009) Speciation and the evolution of gamete recognition genes: pattern and process. Heredity 102:66-76

Patil S, Sandberg A, Heckert E, Self W, Seal S (2007) Protein adsorption and cellular uptake of cerium oxide nanoparticles as a function of zeta potential. Biomaterials 28:4600-4607

Persson M, Räsänen K, Laurila A, Merilä J (2007) Maternally determined adaptation to acidity in Rana arvalis: are laboratory and field estimates of embryonic stress tolerance congruent? Can J Zool 85:832-838

Pespeni MH, Sanford E, Gaylord B et al (2013) Evolutionary change during experimental ocean acidification. Proc Natl Acad Sci USA 110:6937-6942

Picker MD, Mckenzie CJ, Fielding P (1993) Embryonic tolerance of Xenopus (Anura) to acidic blackwater. Copeia 1993:1072-1081

Pierce BA (1985) Acid tolerance in amphibians. Bioscience 35:239-243

Räsänen K, Green DM (2009) Acidification and its effects on amphibian populations. In: Heatwole $\mathrm{H}$ (ed) Amphibian biology, vol. 8. Decline: diseases, parasites, maladies and pollution. Surrey Beatty, Chipping Norton, pp 3244-3267

Räsänen K, Kruuk LEB (2007) Maternal effects and evolution at ecological time-scales. Funct Ecol 21:408-421

Räsänen K, Laurila A, Merilä J (2003a) Geographic variation in acid stress tolerance of the moor frog Rana arvalis. I. Local adaptation. Evolution 57:352-362

Räsänen K, Laurila A, Merilä J (2003b) Geographic variation in acid stress tolerance of the moor frog, Rana arvalis. II. Adaptive maternal effects. Evolution 57:363-371

Räsänen K, Soderman F, Laurila A, Merilä J (2008) Geographic variation in maternal investment: acidity affects egg size and fecundity in Rana arvalis. Ecology 89:2553-2562

Renberg I, Korsman T, Anderson NJ (1993) A temporal perspective of lake acidification in Sweden. Ambio 22:264-271

Salthe SN (1963) The egg capsules in the Amphibia. J Morphol 113:161-171

Seip HM, Tollan A (1978) Acid precipitation and other possible sources for acidification of rivers and lakes. Sci Total Environ 10:253-270

Seymour RS (1994) Oxygen diffusion through the jelly capsules of amphibian eggs. Isrsel J Zool 40:493-506

Shu L (2014) The molecular basis of embryonic adaptation to acid stress in amphibians. PhD dissertation Nr. 22319, ETH Zürich, Zürich. doi:10.3929/ethz-a-010361827

Varki A (2011) Evolutionary forces shaping the golgi glycosylation machinery: why cell surface glycans are universal to living cells. Cold Spring Harb Perspect Biol 3 pii: a005462. doi:10.1101/cshperspect.a005462

Wong JL, Wessel GM (2006) Defending the zygote: search for the ancestral animal block to polyspermy. Curr Top Dev Biol 72:1-151

Yurewicz EC, Oliphant G, Hedrick JL (1975) Macromolecular composition of Xenopus laevis egg jelly coat. Biochemistry $14: 3101-3107$ 